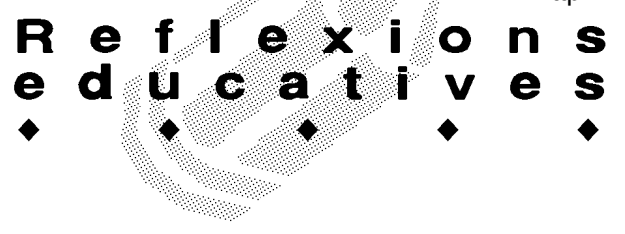

\title{
EL PERFUM DELS SONS
}

\author{
Joaquim Icart Garcia. Àrea de Música. URV
}

\section{Una introducció breu}

És ben cert que les persones, a diferència dels animalons, ens comuniquem simbòlicament. Una simbologia que ens permet transmetre des de les sensacions més primàries fins als conceptes més abstractes. Pel camí, hi trobem des de la representació de les vivències i les imatges fins a les argumentacions matemàtiques que són més lluny de la nostra realitat immediata. Entre l'un i l'altre extrem hi trobem l'expressió artística, la qual, lluny de ser una expressió directa i immediata dels nostres sentiments i sensacions o una simple informació codificada d'aquestes, emprèn també el vol de la simbolització a partir de la qual ens podem fer sabedors d'experiències espirituals comunes a través de les formes simbòliques.

Unes formes simbòliques, en aquest cas musicals, que si bé prenen la matèria o substància sensible directament dels sons, els signes o les figures que defineixen cadascun d'ells, fan referència al valor quantitatiu d'algun dels dos aspectes fonamentals: l'altura, i la duració. A tall d'exemple, podem observar aquesta peculiaritat en aquesta tabulatura per a llaüt del Renaixement, de la dansa dedicada a Isabelle Este de la família Gonzaga de Màntua. Tots els signes fan referència a valors quantitatius, ja siguin xifres, o figures. Signes que han anat canviant la forma a través dels segles, segons la utilitat pràctica, i s'atribueixen sempre als mateixos valors quantitatius dels sons. Actualment, aquestes figures musicals, sobretot pel que fa a la notació del llaüt, han canviat totalment i s'han de transcriure als signes i configuració actual perquè el gran públic acostumat a la moderna notació les pugui interpretar correctament.

Tanmateix, en aquest article intentaré centrar-me en el simbolisme musical a partir de les experiències imme-

Intauolatura di Liuto, con la Mufica, della Sonata del Balletto Efte Gonzaga, fatta in quattro Tempi.

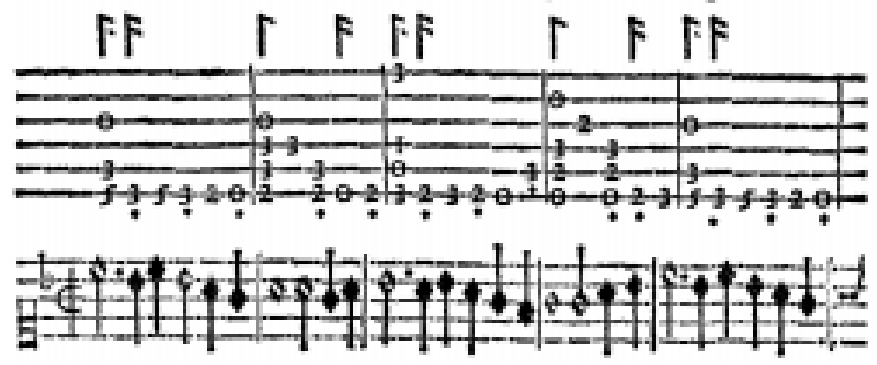

Primers compassos d'una dansa veneciana del s. XVI. De /l Ballarino, de Fabritio Caroso (1581). diates que li donen forma. Unes experiències allunyades del que es podria entendre com a percepcions passives, gairebé fotogràfiques, com les de la persona que rep només una informació sensorial que guarda dins la memòria i de la qual només pot fer un reconeixement posterior al mateix nivell que ho pot fer qualsevol animaló, o com a màxim, assenyalar-la, o significar-la, a través d'algun model semàntic de comunicació.

El meu interès és centrar-me en la intenció focalitzadora de l'enteniment durant la nostra experimentació sensible. Una activitat suggeridora, si no creadora, que li dóna sentit transcendent, del qual podrem extreure una idea musical que serà la base per a la posterior composició musical. Per això, els músics diem que "componem els sons", i no pas que "componem amb els sons", ja que no es tracta d'agafar-ne uns quants i fer-los anar pel dret, sinó de compondre'ls, de posar-los al lloc que els correspon dins la idea. No es tracta d'agafar-los de fora, sinó que ja es troben tots dins la concepció musical. Aquest darrer aspecte és fonamental per comprendre l'abast de l'experiència musical des del vessant purament sensorial $\mathrm{i}$ vivencial.

Procuraré mostrar tot el valor $i$ tota l'esplendor d'aquestes vivències significatives donades a la nostra consciència a través de la pura substància sonora. Així, primer de tot, intentaré, encara que metafòricament, fer-les lluir a través d'alguns exemples hipotètics de la nostra experiència sensible. Vivències de la substància sonora alhora imprescindible per a qualsevol estructuració formal i codificació futura com a llenguatge que se'n pugui derivar.

\section{Sobre la resistència de les sensacions al simbolisme}

Les nostres experiències sensibles immediates, assolides a través dels nostres sentits (vista, oïda, olfacte, gust i tacte), es resisteixen al simbolisme en general $i$, d'una manera encara més tossuda, a la codificació explícita segons les diverses manifestacions. Així, per exemple, pel que fa a les olors, només utilitzem dos mots per classificar-ne el gènere. Anomenem perfumades les coses que fan bona olor o fragància, o bé diem que fan pudor, fàstic, etc., quan notem que fan mala olor. És a dir, que només sabem posar nom a les sensacions olfactives en els dos sentits diametralment oposats respecte a les nostres experiències: agradables o desagradables.

Si hi posem una mica d'atenció, veurem que qualse- 


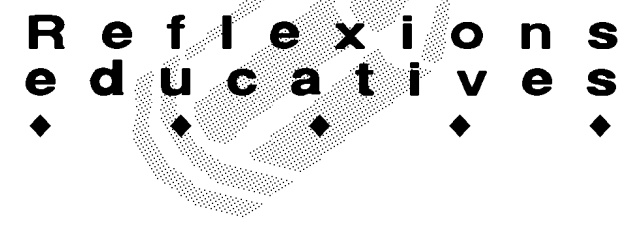

vol olor o perfum pren el nom de la cosa a la qual ens referim, però no pas a la peculiaritat olfactiva per si mateixa. Així, fem referència a les olors de rosa, de clavellina, etc., i és pràcticament impossible posar un nom propi a un perfum per si mateix, sense haver de referir-nos a l'objecte que ens provoca aquella experiència olfactiva. Fins i tot, quan hom descriu el perfum d'un determinat vi, ha de manllevar adjectius relatius a d'altres coses aromàtiques ja conegudes. Per definir aquell perfum no som capaços d'assignar-li un nom específic, sinó que n'hem d'emprar molts d'altres, relatius cadascun a altres coses amb perfums diversos, i així, d'una manera general, parlem de perfums de diverses fruites. Fins a tal punt el mot olorés orfe de qualitats objectives a les quals ens referim d'una manera universal -depèn del sentit de la nostra mateixa subjectivitat- que l'apliquem fins i tot a qualitats humanes, com en l'expressió "va morir en olor de santedat", per referirnos a la impressió espiritual que ens va produir aquella persona i que ens va afectar de manera vivencial i afectiva.

El mateix podríem dir del gust i del tacte i, pel que fa als colors, només som capaços de definir amb nom propi els colors primaris purs i els secundaris respectius. Per a molts altres matisos, encara que molt propers als colors primaris, tenim necessitat d'una definició objectiva amb el nom del que se'ns presenta. Així, ens referim als colors verd maragda, oliva, blau turquesa, marí, cel, vermell fúcsia, taronja, groc llimona, siena, etc.

Si ara fem una reflexió sobre aquesta peculiaritat de les sensacions olfactives dels nostres sentits, veurem que més que resistir-se a la simbolització, són el mateix símbol de l'objecte a través del qual es manifesten. L'olor d'una flor, la mateixa olor, és la que li pertany i la que la defineix i diferencia d'altres. Només així les olors prenen forma pròpia en la memòria i en les vivències.

De la mateixa manera que el rostre de la nostra mare es reflecteix en la nostra memòria com una imatge vital, el perfum de la rosa també ens mostra experiències vitals irrepresentables simbòlicament, i només a través de la nova experiència sensorial revivim la plenitud espiritual. Precisament, aquesta capacitat evocadora i no pas designadora o senyalitzadora que tenen aquestes qualitats sensorials és la que explica la funció ritual i litúrgica en els esdeveniments socials de totes les èpoques i cultures, i a les quals la moderna antropologia, i bona part de lapsicologiacomparada, hi hadedicatles sevesmillorsinvestigacions. Lluny d'actuar com a representants dels valors, el que fan és reviure en collectivitat les corresponents sensacions individuals. L'olor de la resina de l'encens, per exemple, ens desperta i ens endinsa en les magnificències litúrgiques, alhora que les imatges només són l'exponent visible i significatiu del tema en concret.

Qui de nosaltres en sentir l'olor característica del nostre poble després d'una bona temporada d'absència no ha notat una sensació especial de pertinença, de formar part substancial d'aquell poble? Aquella olor ens pertany, és part de la nostra existència. Cap descripció ni visió dels colors ni del seu entorn seria capaç de fer notar, tot d'un cop, tota la magnificència i totes les vivències que portem amagades dins la memòria. Només l'olor ens dóna la certesa absoluta de ser al nostre poble, en un determinat Iloc, a l'escola; la nostra escola, amb la seva olor inconfusible. Notar l'olor d'una escola transforma l'ànim de forma immediata: ens notem mestres, amb tot el neguit $i$ reguitzell de sensacions i emocions que això comporta.

Ara bé, a una simple olor que tanta informació ens dóna de forma immediata no li sabem donar un nom. Potser sí que la podríem denominar, per exemple, l'olor $A$, però és possible que després d'un temps i de tants noms per a tantes olors, ens oblidéssim del nom que hem posat a cada una i de l'olor corresponent al nom amb la qual la vam designar. Algú és capaç d'imaginar-se una mostra de perfums només amb signes?

\section{Sobre el valor significatiu dels noms de les nostres sensacions}

La primera cosa que ressalta sobre les olors és que, precisament, el nom que designa una olor no es refereix a l'olor mateixa, sinó a l'objecte del qual és la propietat. Així, anomenem flor, com a nom genèric, una determinada constitució o estructura formal del món vegetal i amb el mot rosa designem una determinada espècie a partir de la qual es poden nomenar moltes varietats. Doncs bé, l'olor d'una flor ens evoca la d'una espècie, per exemple, l'olor de la rosa, o fins i tot d'una de les seves varietats, la rosa salvatge. Si algú no ha experimentat l'olor d'aquesta rosa, podrà descobrir-la de nou, però no identificar-la amb una sola imatge. Alhora, hi haurà persones que amb una capacitat olfactiva dèbil no seran capaces de distingir varietats d'olors. En tot cas la designaran de la mateixa manera que designaran un cavall, amb la paraula que la denomina, però no amb l'olor de la flor a través de la imatge Així, doncs, és l'olor mateixa i la seva evocació olfactiva la que ens recorda la d'una determinada flor i no a l'inrevés.

Una de les preguntes que proposava a l'assignatura de Metodologia Elemental de la Música feia referència a la capacitat per reconèixer una persona pel seu nom al cap de molt de temps. El problema es plantejava pel fet que aquella persona es deia Rosa i, en haver-n'hi tantes, hom no podia identificar-la pel seu nom en concret. Així, doncs, un s'esforçava a donar detalls i, al cap de molta estona, recordava que aquella Rosa era la de cal Pep: Ah, sí, aquella noia, tal i tal.., però no es deia Rosa sinó Roser. No era el nom, doncs, allò que ens portava a aquella noia, ni els detalls del cabell, ni de la veu, etc. $\mathrm{Hi}$ havia un detall, però, que havia evocat les vivències compartides amb aquella persona i, per tant, havia permès identificar-la com la de cal Pep. A cal Pep i en cap altre 


\section{ก.}

lloc ella havia jugat i viscut moltes estones amb aquells mobles, parets, olors i alegries, etc.

Vegeu, doncs, quin era el símbol representatiu de la

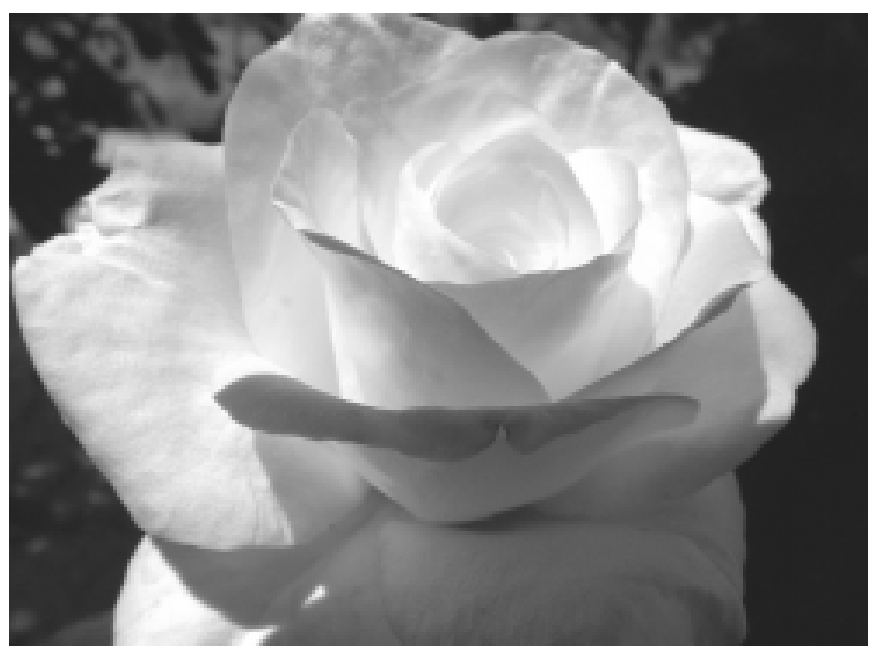

Una rosa esplendorosa d'una fresca fragància. Noteu aquesta fragància en veure la seva bella figura?

Roser! No era el nom, ni el color dels cabells, ni la bellesa, ni el caràcter; no era cap representació seva, sinó les meves vivències a cal Pep amb ella. Veiem quin paral.lelisme hi ha entre la funció simbòlica de cal Pep i les olors. De la mateixa manera, les vivències anomenades de cal Pep han evocat la Roser, com l'olor de rosa a la seva flor. Comproveu com la fotografia d'una rosa no evoca d'una manera espontània la seva sensació olfactiva. Si ho voleu aconseguir, no us toca més remei que fer memòria d'alguna experiència olfactiva, però no pas a través de la fotografia que teniu al davant. En tot cas, la imatge us pot representar una experiència sensorial passada, de la mateixa manera que ho pot fer la imatge del rostre de la vostra mare. La idea de la mare evoca, no simboliza. Representarà la seva persona només per a aquells qui no la coneixen personalment, com ho pot fer el retrat de Felip II al museu del Prado, que fa referència al rei que va viure durant la segona meitat del segle XVI.

\section{De com identifiquem els valors de les nostres expe- riències sensorials}

Tinc confiança que aquestes consideracions anteriors hagin deixat una mica clara la substància sensorial de les nostres experiències immediates i la possibilitat nul.la d'actuar com a símbol, ja que no es refereixen a cap objecte en concret sinó a les nostres vivències individuals $\mathrm{i}$ intransferibles. Tanmateix, també confio que es podrà entendre que sense aquestes experiències sensorials, emocionals i vivencials, en general, no hi queda res per representar simbòlicament i, per tant, no hi té cap sentit un llenguatge codificat, ja que no hi ha res per designar.

\section{Poden definir valors discrets els sons com a codis sig- nificatius?}

Si acabem de veure que les experiències sensorials $i$ les vivències no poden actuar com a símbol, per què un llenguatge musical? Quin sentit tindran els codis significatius, quina funció faran i què designaran? Possiblement, en considerar que els codis musicals es refereixen a una substància vivencial que no té res a veure amb l'objecte al qual ens podem referir explícitament, els teòrics de l'educació els considerin menys estrictes i inestables, i pertanyents a un llenguatge del seu propi gènere i inferior al verbal i al matemàtic.

Al meu parer, aquesta és una confusió monumental en l'aplicació dels conceptes semàntics: entre els significants i el significats, pel simple fet que el discurs musical no assenyala, no apunta cap a res, no intenta significar cap qualitat a la nostra imaginació, i encara menys cap valor quantitatiu, ja que és aquesta, precisament, la mateixa substància dels sons en el seu valor discret. El discurs musical no "significa", el discurs musical "evoca".

Ara bé, si el discurs musical no significa res i no és símbol de res, d'on surt el seu llenguatge i els codis capaços d'evocar? Caldrà analitzar, en primer lloc, exactament d'on surten aquests valors discrets o codis evocadors. En segon Iloc, i en el cas que trobem aquests valors discrets, seran ells mateixos els que tindran el poder evocador? Dit d'una altra manera, tindran el do del perfum, com les flors?

En el cas dels colors, la natura ens regala matisos infinits d'aquelles qualitats, però hem vist la dificultat de codificarlos cadascun d'una manera universal i objectiva. Podem comprendre, doncs, que de l'experiència enriquidora immediata no podríem extreure'n codis significatius que ens permetessin assolir un llenguatge universal, ja que en cada cas tot depèn de les qualitats immediates experimentades individualment. En el cas dels sons, la cosa es complica encara més, ja que la natura no ens dóna de manera espontània tota la gamma discreta d'altures, ni de timbres, ni de successions sonores, encara que només sigui a través d'algunes formes esquemàtiques, per simples que siguin. Així, a què ens referirem quan parlem de llenguatge musical?

\section{D'on ens vénen les notes musicals i els valors que re- presenten?}

Primer de tot, considerant el so des d'un punt de vista purament teòric, observem que l'emissió és fruit d'una vibració, la qual es desplaça en forma d'ones a través de qualsevol mitjà que les propaga. Per a nosaltres, el medi normal és l'aire i els seus valors els quantifiquem segons l'amplitud de les ones, per la seva freqüència vibratòria, etc. Ara només ens interessa la freqüència, la qual ens proporciona tota l'amplitud de sons, des del més greu fins al més agut, tal com ho fa la sirena, que ens dóna el 


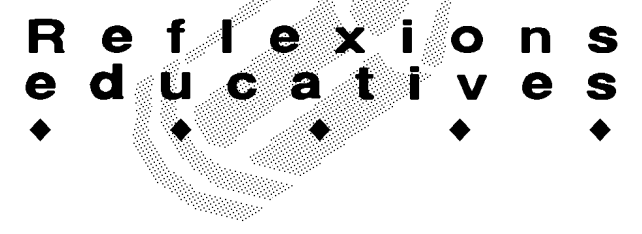

continu sonor des del so més greu audible per l'humà fins al més agut, sense parts discretes, o sense intervals sonors diferenciats. Quantitativament i expressat aquest àmbit sonor en hertz - unitat internacional de freqüència d'una vibració-, o nombre de vibracions per segon, una oïda normal pot copsar sons des de 16 fins a 20000 hertz. Tot plegat, molt interessant, però, i els sons de l'escala musical, on són?

L'origen de la música està associat al cant dels ocells. Tanmateix, l'actual antropologia cognitiva considera el seu origen no tant en la mateixa natura com en la capacitat humana d'estructuració discreta del continu sonor en sons d'altura determinada i amb ells la capacitat d'estructuració formal d'un discurs musical.

\section{El so com a continu i com a interval discret}

Els estudis antropològics de les primitives civilitzacions ens fan entendre que l'home va començar a distingir els intervals corresponents amb els principals harmònics, és a dir, intervals d'octava, de quinta, de quarta, etc. Tanmateix, no eren encara intervals afinats tal com ho entenem en la música culta, sinó que eren senzillament salts de veu aproximats a aquests senzills intervals que es corresponien amb l'expressivitat de l'argument cantat. Formes de cantar que encara podem escoltar en músiques populars i que encara han pogut conservar l'essència ètnica.

Vist molt ràpidament, la seva evolució cultural va derivar en múltiples formes del que anomenem escales musicals. A l'Orient es va definir l'escala pentatònica, formada per cinc parts discretes dins l'àmbit de l'harmònic de quinta. Posteriorment a aquesta escala se li va aplicar una nova divisió, la qual es corresponia amb un to mitjà entre el tercer i quart grau d'àmbit pentatònic. La unió de dues d'aquestes escales va configurar finalment l'escala diatònica que encara utilitzem. L'àmbit d'aquesta escala es correspon amb l'actual octava, és a dir, l'àmbit que va des d'un determinat nombre de vibracions per segon o hertzs, fins a arribar al seu doble. Les possibles fraccions intermèdies són les que van donant les diverses altures de to: a partir del fonamental o primer i més greu, fins a arribar al més agut o darrer. Actualment, aquestes parts discretes del continu sonor dins l'àmbit d'una octava, dotze en total, prenen els valors dins d'una progressió logarítmica. No cal dir que aquestes divisions van comportar, des de l'antiguitat i a partir de l'originària escala tetracordal, nombroses especulacions teòriques i experimentacions pràctiques en l'afinació intervàlica pel fet que els cants eren molt melismàtics i en conseqüència les altures tonals anaven molt lligades a aquestes fluctuacions tan riques en capacitat expressiva. En aquest aspecte, només cal esmentar que Ptolomeu en la seva Harmònica cita 15 formes diferents de divisions tetracordals.

La música, fins ben arribada l'edat mitjana, era pu- rament melòdica però no per això era una música menor. Pel que fa a la música anomenada d'Occident, tenim un tresor formidable en el cant gregorià. A través de la seva senzillesa podem gaudir del que en podríem dir la música més pura, basada en petites fluctuacions intervàliques dels sons, d'acord amb la intensitat emotiva del text. Cadascuna de les variacions en l'altura del so no és gratuïta, ni per fer bonic. L'ésser humà ha estat capaç de descobrir en aquestes fluctuacions intervàliques una bellesa immensa i un plaer espiritual. Tanmateix, no es tracta de successions qualssevol, sinó que la successió que es correspon en cada cas es deriva del gust estètic, el qual ja no és conseqüència de la capacitat de discreció de l'enteniment, sinó d'una capacitat molt més elevada, la qual és un misteri inexplicable que rau en el més profund de l'esperit humà.

Així, des d'un continu sonor, que podem exemplificar a través de la progressió sonora d'una sirena fins a arribar a la bellesa que ens proporcionen els seus salts intervàlics, hi ha hagut un treball de recerca sonora de segles. Un resultat que, malgrat uns bons sentiments espirituals, no hauria estat possible sense la capacitat discrecional de l'enteniment, però tampoc hauria estat capaç de descobrir la bellesa d'aquestes parts discretes i l'harmonia musical del perfum o fragància musical sense el sentit estètic.

\section{Sobre els noms dels sons}

Segur que tothom ha experimentat alguna vegada l'impacte sentimental produït per una melodia, que ens ha evocat vivències passades que tornem a reviure com si el temps no hagués passat. Doncs bé, si els sons són tan capaços, més que les olors, d'actuar com a evocadors que ens porten directament al centre de la consciència, allí on donem fe de la nostra vida amb els sentiments $i$ amb la importància de les relacions intervàliques, de les quals es deriven les melodies, podríem comparar-los amb els diversos perfums de les flors.

Vist així, nomenar els valors intervàlics seria, com a mínim, igual de subtil que posar nom a les olors. És més, possiblement ens pugui passar com a l'anècdota de la Rosa i de la Roser, a la qual no la definia ni el nom, ni els cabells, sinó que la identificava el fet de ser de cal Pep. Podia haver estat tot igual a cal Joan; però no, era a cal Pep, com el nom d'una flor a la qual pertanyia el perfum que definia les vivències experimentades jugant amb la Roser. Així, tot i que cal Pep era el nom exclusiu amb possibilitat d'identificar la Roser, també era un nom circumstancial. Veiem, doncs, que no era ni el nom de la Roser ni els atributs, i ni tan sols cal Pep o cal Joan, sinó la relació vital entre el nom cal Pep i les vivències que ens evocava, com el nom de la flor ho feia amb el seu perfum. Nom i vivència eren indissolubles, però només per a 


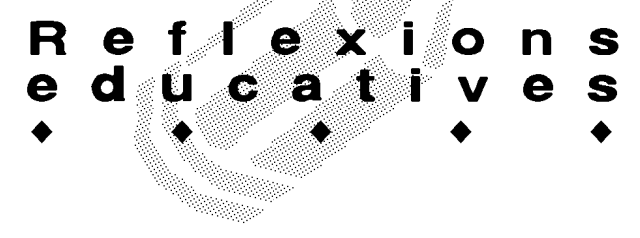

aquella singularitat vital. Fora d'aquest context, cal Pep perdia tot el valor evocador.

Què pot significar ara per a nosaltres, respecte als sons, la propietat de ser de cal Pep? Posar el nom a un interval (que es podria correspondre amb una qualitat expressiva sonora anàloga a una propietat olfactiva), és molt agosarat, ja que és l'olor, o en aquest cas la qualitat sonora de l'interval allò que ens descobrirà la vivència. Doncs bé, si en el cas de les olors els perfums particulars ens evoquen la flor, o ser de cal Pep la vivència de la Roser, en el cas dels sons, què ens evoquen les relacions intervàliques, 0 millor dit, a què ens dirigeixen com a propietat sonora?

No podem obviar que posem els noms de les olors a les flors i no a les olors mateixes. En el cas de les relacions intervàliques, si el perfum estètic es deriva d'aquestes relacions, els noms s'hauran de correspondre amb els valors dels seus intervals sobre els quals recau la qualitat estètica. Doncs bé, si tenim en compte que aquests intervals (cadascun amb el seu valor discret dins el continu de l'àmbit d'una octava) ho poden ser en sentit ascendent o descendent dins d'una zona superior o inferior de l'escala, com podrem posar els noms si els mateixos valors es poden combinar d'infinites maneres? Doncs bé, no toca altre remei que preguntar-nos si realment el perfum musical és una propietat dels intervals o bé ho és segons l'entorn intervàlic que l'acompanya, tant abans com després de la seva expressió sonora. ¿Podem dir que un interval és bell, per si mateix, o bé adquireix la bellesa singular en cada moment segons una determinada forma de relacionar-se amb l'antecedent i el conseqüent? Quan ens mostri tota la bellesa adquirida, el seu nom serà el dipositari d'aquest perfum musical. Així, amb el mateix nom, una mateixa relació intervàlica ho podrà ser d'una quantitat infinita de perfums sonors i evocar infinitat de vivències.

Veiem, sinó, com adquireixen perfum els sons dels intervals. Si observem la veu del violí primer dels primers compassos d'aquest Quartet de Beethoven, veurem que el seu moviment intervàlic és, precisament, l'element estètic bàsic que aporta una enorme capacitat expressiva. Poques vegades amb tan poques notes s'han expressat sentiments tan profunds i elevats espiritualment. Un senzill interval descendent des del cinquè grau a la tònica per retornar altra vegada al mateix lloc en un moviment ascendent i descansar finalment sobre l'interval del tercer grau. Així de senzill, aquest moviment d'ascens i de descens ens provoca una delicada sensació de tensió i distensió.

Desenvolupat aquest moviment sobre la coloració menor de la tonalitat de fa, la primera nota melòdica no baixa de cop a la tònica, sinó que inicia una mica d'elevació fins a l'interval de tercera, rodola sobre el grau imme- diat inferior, i es deixa caure finalment sobre la tònica (fa) des d'una distància de sisena menor. En la caiguda, però, fa com si s'arronsés i decau mig to per sota, per tornar-se a enlairar un altre cop fins al cinquè grau, i d'allí descansa sobre el tercer grau, ondula de forma decreixent i passa per un interval de quarta, de tercera, i finalment de segona. Així de senzill i així de meravellós. És l'harmonia! Els intervals que sonen alhora completen tota la força expressiva de la melodia. Tot va d'intervals! Que en són, de formosos, i com sonen aquests intervals!

Doncs bé, quants intervals de cinquè grau, de quart, etc., hi ha en totes les melodies? Tots són iguals sempre tenen el mateix valor intervàlic $i$ estan lligats a la sort que els ofereix l'aventura melòdica o harmònica que els toca viure. Tots tenen el mateix valor proporcional dins l'escala musical, però no tenen ni personalitat ni perfum, ni fragància. Podríem dir que el nostre interval de cinquè grau del Quartet de Beethoven és com la Roser de cal Pep. Aquella Roser no era qualsevol Roser que recordéssim d'un altre lloc, a la qual confonguéssim el nom; era ella, aqueIla Roser amb la qual havia experimentat moltes alegries en la meva infantesa, la de cal Pep. I cal Pep no era el que coneixia tothom, era la flor per a la Roser, d'on venia el seu perfum, la pròpia vivència.

Quin sentit té, doncs, el valor d'un interval agafat al vol i sense cap context intervàlic que pugui manifestar el seu perfum? És com una flor sense olor. Un interval sol només és un valor acústic. Si només aprenem el valor acústic o només aprenem la tècnica d'afinar-lo bé, aconseguirem això: afinar-lo i saber-lo escriure i llegir, ¿però, haurem aconseguit conèixer $i$ identificar-ne algun de tan preciós com quan vam reconèixer la Roser? De moment,

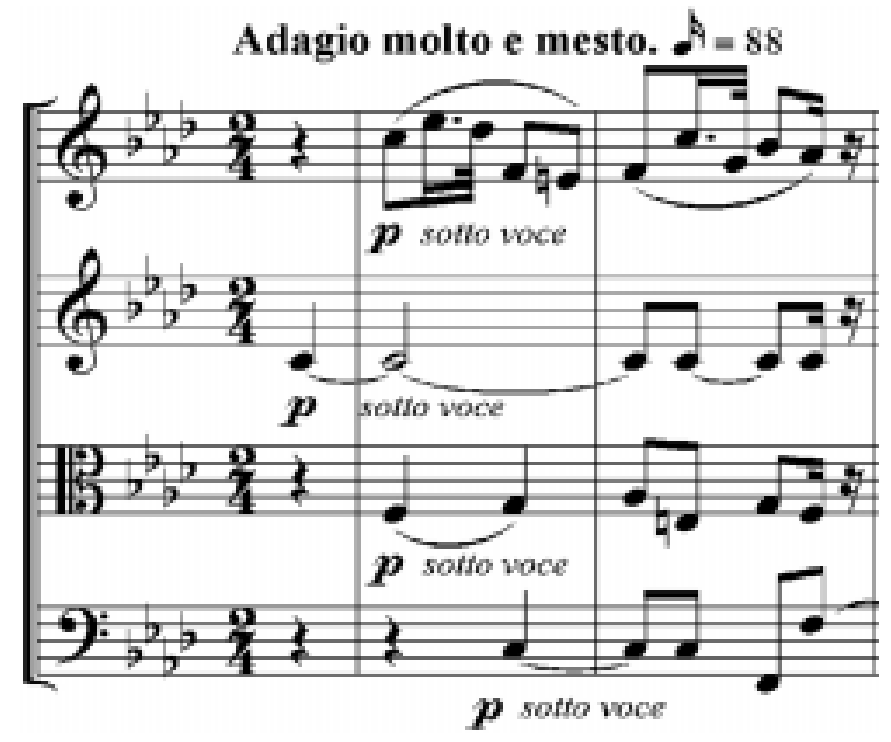

Primers compassos del tercer moviment del Quartet en fa major Op. 59/1 de L.V. Beethoven. 


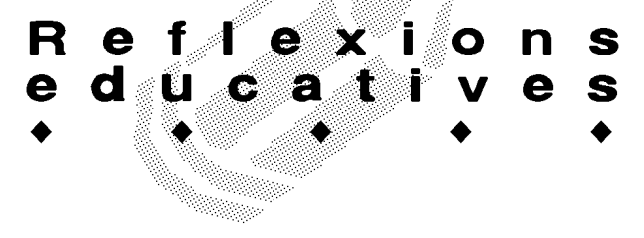

nosaltres n'hem identificat uns de meravellosos, els de l'inici del Quartet Op. 59/1 de Beethoven. N'hi ha molts més. Ja teniu feina! I no només d'aquests valors! I què en direm del cant gregorià, quina meravella, fet de petits intervals tan ben arrenglerats, que s'emporten pels aires l'expressió senzilla de les paraules, del discurs, de les emocions espirituals!

I encara més petits i minsos poden ser els intervals sense que això els faci perdre la més mínima expressivitat. Si no, vegeu amb quina timidesa de moviments es mouen els intervals en aquest Preludi Op. 28 n 4 de Chopin.

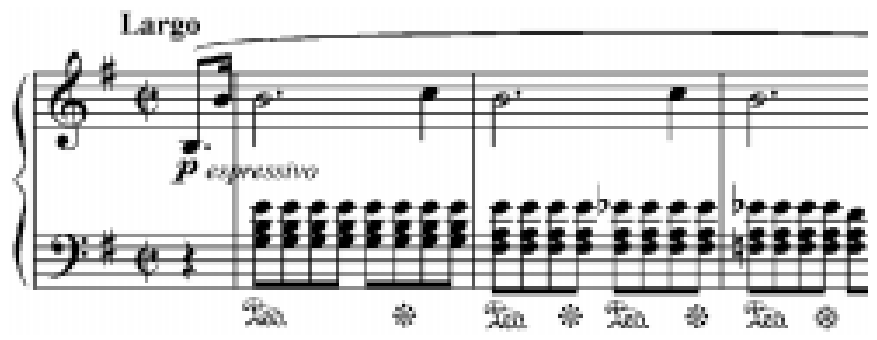

Primers compassos del Preludi núm. 4, Op. 28 de F. Chopin.

Bastit en tonalitat menor, comença amb un sobtat salt d'octava, cap a les altures, com de profunda admiració, per mantenir-se allí amb unes petites fluctuacions de mig to, com si aguantés la respiració d'emoció. Mentre, a sota veu, els acords repetitius acompanyen el sentit de l'alè de la veu superior. Uns acords amb inversió primera, que deixen sentir la seva veu dolça com una remor que anirà decreixent de mig to en mig to, com qui es deixa emportar extasiat cap a la pau, fins a baixar a una distància de cinquena, on en un crit d'autèntica emoció recupera l'estat inicial de la tensió, etc. Escolteu-lo quan pugueu! Uns intervals on l'altura dels sons amb prou feina es mou, i, en canvi, poden calar profundament en el nostre esperit i suggerir-nos tantes coses, i amb tanta plenitud espiritual.

Diem que una flor no fa estiu. I un interval sol tampoc no fa música. I menys encara les notes. Què fa una nota sola? Una nota sola ni vol dir res ni dóna cap altura determinada, o pitjor encara, qualsevol altura de so pot tenir qualsevol nom de totes les que hi ha a l'escala musical. Al revés dels noms que posem a les coses! Un interval sol és com la flor, a la qual posem un nom, però li falta el perfum. És com la Rosa, que al final va resultar ser la Roser. Nosaltres volíem trobar aquella noia en concret, però el nom no la designava. Cal Pep tampoc no era un nom com els altres, era com el perfum d'una flor que m'evocava, només escoltar-lo, les vivències amb la Roser.

En tot cas, dues notes ens poden donar els límits d'un interval, el qual continuarà a mercè de la posició que li donem dins de l'escala musical. Ah, i l'escala musical, què és, doncs? Doncs és ella mateixa un interval. L'in- terval que prenem per unitat. Tota la resta d'intervals prendran els valors de manera proporcional al valor d'aquesta unitat, i res més.

\section{Consideracions finals}

Per arrodonir aquesta reflexió, no he trobat res millor que reproduir unes paraules d'Ernst Cassirer (1971), possiblement l'estudiós més gran de les formes simbòliques de la nostra cultura: "Cuando el sonido físico, diferenciable como tal sólo a través de las notas de la altura o la gravedad, intensidad y cualidad, se constituye en fonema, se vuelve expresión de las más sutiles diferencias racionales i sentimentales. Lo que inmediatamente es, pasa ahora completamente a segundo término frente a lo que mediatamente logra e 'indica'. Aun los elementos individuales concretos a partir de los cuales se estructura una obra de arte muestran claramente esta relación fundamental. Ninguna creación artística puede entenderse como la simple 'suma' de estos elementos, sino que en cada uno opera una ley determinada y un sentido específico de conformación estética. La síntesis en la cual enlaza la conciencia una serie de tonos en la unidad de una melodía, es de aquellas gracias a las cuales una multiplicidad de fonemas se unen para nosotros en la unidad de una 'oración' manifiestamente distinta. Pero todas ellas tienen en común que en ambos casos las unidades sensibles no permanecen aisladas, sino que se insertan en un 'todo' de la conciencia, recibiendo sólo de éste su sentido cualitativo".

Tanmateix, hem d'entendre que, així com els fonemes s'articulen en paraules i les paraules en frases significatives per proposar-nos un joc imaginatiu que faci impacte en la nostra consciència, els intervals sonors no indiquen ni designen res, ni desperten en nosaltres cap activitat imaginativa, sinó que ens penetren de cop en el més profund de la consciència, directament i sense metàfores. També hem pogut comprovar que els valors dels seus codis, els intervals, pertanyen al regne de les quantitats matemàtiques, i per aquest motiu el seu llenguatge és universal, no té idiomes i no necessita traductors com en els colors. Així, igual que el perfum l'atribuïm a les flors sense que es descriguin per si mateixes i es posin un nom, els perfums dels intervals d'una composició musical són de cadascun de nosaltres i tampoc es descriuen com a "universals"; pertanyen exclusivament a aquella flor única composta pels intervals musicals que li són propis, els quals ens fan notar el perfum de les vivències i sentir-les al moment!

\section{Referències bibliogràfiques}

CASSIRER, ERNST. Filosofía de las formas simbólicas. (3 vol.). Edit. Fondo de Cultura Económica. México. 1971. 